\title{
The Impact of Renewable Energy Consumption to Economic Growth: A Panel Data Application
}

\author{
Roula Inglesi-Lotz \\ Department of Economics, University of Pretoria, South Africa
}

\begin{abstract}
Internationally, the importance of renewable energy in the energy mix has been increasingly appreciated. The advantages of the renewable energy usage for the world's energy security and the environment are indisputable and much discussed in the literature. However, its effects on the economic welfare of the countries are yet to be examined fully and described quantitatively. The purpose of this paper is to estimate the impact of the renewable energy consumption to economic welfare by employing panel data techniques. The results show that the influence of renewable energy consumption or its share to the total energy mix to economic growth is positive and statistically significant. From a policy point of view, promoting renewable energies bears benefits not only for the environment but also for the economic conditions of the countries.
\end{abstract}

Keywords: Renewable energy; economic welfare; OECD countries; panel data analysis 


\section{INTRODUCTION}

It is without doubt that one of the most severe problems of the modern world is the climate change and its important negative consequences to the environment. Human activity, particularly the consumption of energy, has been considered among the main factors contributing to the changing of climate in the last decades (IPCC, 2007). To tackle the future changes of the environment, among other measures, a change in the current technologies of generating energy is imperative. Traditional generation techniques such as coal-burning have detrimental effects to the environment and hence, internationally, countries have turned towards more environmentally-friendly generation techniques from renewable sources such as solar and wind.

The Energy Information Administration (EIA) reports that the generation of energy through renewable sources has been the fastest growing source recently (EIA, 2009). Developed economies promote renewable sources in order to strengthen the energy security of supply and control their greenhouse gas emissions (GHG) (Moselle, 2011). For example, the European Commission aims to increase the share of renewable sources to $20 \%$ of the total by 2020 (EC, 2009). On the other hand, the developing economies see in the use of renewable energies, solutions to the challenges of rural electrification and lack of access to electricity (Munasinghe 2010, Perreira et al. 2010). For example a large proportion of the African population has no access to electricity, even though the continent has great abundance of alternative and renewable energy sources such as solar, thermal, photovoltaic, wood, biomass, wind and biogas. Kaygusuz et al. (2007) and Kaygusuz (2007) also mention that the choice to promote renewable energies will lead not only to further modernization of the energy sector but also support the various countries' goals for economic development and sustainability.

The purpose of this paper is to determine quantitatively the impact of renewable energy consumption to the economic conditions in a panel data framework including all the OECD countries for the period from 1990 to 2010. The results of this analysis have important implications for the implementation of future policies on promoting renewable energies in combination with macroeconomic policies. The importance of this paper lies with the fact thtat it takes into account the importance not only of the volumes of renewable energies consumed but also their share in the total energy mix of each country; an indicator that shows the importance of renewable energies in a country's energy planning and future. Moreover, this paper uses a sound 
theoretical framework, assuming that the renewable energies are part of the production capacity of a country.

The paper is structured as follows. Section 2 discusses briefly international literature dealing with the nexus between renewable energies and economic growth. The following section discusses the methodology and the data used while next the empirical results are presented. Finally the last section concludes the analysis.

\section{BRIEF LITERATURE REVIEW}

Renewable energy is considered to be in synergy with many aspects of sustainable development (Stigllitz, 2002). That is the reason that sustainable development through renewable energies is at the center of policies all over the world. As Bugaje (2006) mentions, "in making renewable energy consumption sustainable and acceptable to other socioeconomic parameters of development, the following must be considered:

- Sustainability of the environment through appropriate resource management;

- Economic sustainability through infrastructure and service development that keeps affordability firmly to the front because of the disadvantaged rural populations;

- Social sustainability through ensuring that the poor benefit, and that women's incomes and concerns, legal rights for all, and children's rights are all appreciated and supported;

- Administrative sustainability through ensuring that there is administrative capacity for programme implementation and this will be maintained or increased over time."

A number of studies have been conducted showing the importance of renewable energies globally with regard to their relationship to the countries' economic conditions. For instance, Sadorsky (2009) concluded that there is a positive relationship between real per capita income and per capita renewable energy consumption. This result is confirmed by Apergis and Payne 
(2010) who examined the same relationship for the OECD countries in a panel data context. Frondel et al. (2010) focused on the implications of the renewable energy usage to job creation and effective market operations in Germany. Sari and Soyotas (2004) by carrying out a decomposition exercise concluded that waste, hydraulic power and wood consumption explain approximately $31.5 \%$ of the variation in real GDP for Turkey. More recently, Tugcu et al. (2012) examined the renewable and non-renewable energy linkages with economic growth in G7 countries. Their findings showed not only that renewable energy is a contributing factor to economic growth but also that a production function is effective in explaining the relationship. Also, Menegaki (2011) examining the same question for the European countries, found that in the long-run a $1 \%$ increase in the share of renewable energy to the total energy mix will increase GDP by $4.4 \%$.

Although the relationship been discussed in the literature already but not extensively, this paper learns from others and combines their strong points in the analysis. The theoretical framework followed was derived by Fang (2011) and justified by Tugcu et al. (2012). A Cobb-Douglas production function (1928) is used where the technological level of the countries is proxied by the total expenditures for Research and Development (R\&D). Also, two different variables representing the countries' economic conditions are utilized for robustness purposes, as in Fang (2011): Gross Domestic Product (GDP) and GDP per capita. To ensure the robustness of the results and to answer some policy questions, two variables are used to represent renewable energy: the total renewable energy consumption and the share of renewable energy consumption to overall energy consumption of the countries, as in Fang (2011).

The panel cointegration technique proposed by Pedroni $(1999,2004)$ and employed in Apergis and Payne (2010) is also used here. With regards to the data, Apergis and Payne (2010) include only 20 OECD economies while this paper aims at using data of at least 30 of the OECD economies depending on data availability. The time period here spans from 1990 up to 2010, while Apergis and Payne (2010) include data only until 2005. The analysis blends the rational and methodology of Fang (2011) and Apergis and Payne (2010). Fang (2011) looked at the influence of renewable energy consumption and its share to various macroeconomic indicators such as Gross Domestic Product (GDP) and GDP per capita in China; while Apergis and Payne (2010) investigated the relationship for 20 OECD economies. This paper adopts the theoretical 
framework of Fang (2011) that examines the hypothesis within a Cobb-Douglas production function and the econometric methodology employed in Apergis and Payne (2010).

\section{METHODOLOGY}

\subsection{Theoretical model}

The theoretical basis of this focus area lies with the fundamental economics of production as it was used by Fang (2011) in his effort to evaluate the influence of renewable energy consumption to the Chinese economy. In his empirical work followed here, in order to represent a relationship between inputs and output, a Cobb-Douglas functional form is used. This general function has the form of (Cobb-Douglas, 1928):

$$
\mathrm{Q}=\mathrm{A} \mathrm{L}^{\alpha} \mathrm{K}^{\beta}
$$

where $\mathrm{Q}$ is the monetary value of production; $\mathrm{L}$ is the labour input; $\mathrm{K}$ is the capital input, $\mathrm{A}$ is the total factor productivity and $\alpha$ and $\beta$ are the elasticities of labour and capital respectively.

Although the labour and capital variables can be easily quantifiable as the number of employed people in the country and gross fixed capital formation respectively, the technological change can be represented by various variables. Following Fang (2011), in this exercise the R\&D expenditure is used as a proxy to technological changes. Following Fang (2011), two variables will represent the possible influence of renewable energy consumption to economic growth: total consumption of renewable energy and share of renewable consumption to the energy mix. Thus, the final Cobb-Douglas function to be estimated will be as follows in its natural logarithm form (denoted by the small letters):

$$
\operatorname{gdp}(\text { or gdppc })=\alpha_{0}+\alpha_{1} \operatorname{trc}(\text { or src })+\alpha_{2} \text { cap }+\alpha_{3} \text { empl }+\alpha_{4} \text { r } \_d+\mu
$$

where gdp is the Gross Domestic Product and gdppc is the Gross Domestic Product per capita; trc is the total renewable energy consumption; src is the share of renewable energy consumption 
to total energy consumption; cap is the gross capital formation; empl is the number of employees; $r \_d$ is the $R \& D$ expenditure of the each country and $\alpha_{0} \ldots \alpha_{4}$ are the unknown parameters to be estimated while $\mu$ is an error term.

\subsection{Econometric methodology}

The above theoretical model will be estimated using panel data techniques. Firstly, unit root tests will be used to confirm formally whether the variables are stationary or not. A number of unit root tests were considered but most test for a common root among the series. The chosen test was the one proposed by $\mathrm{Im}$ et al. (2003) that tests for unit roots allowing heterogeneous autoregressive coefficients. The equation used to test for unit roots is:

$y_{i t}=\rho_{i} y_{i(t-1)}+\delta X_{i t}+\varepsilon_{i t}$

where $\mathrm{i}=1, \ldots \mathrm{N}$ for each country; $\mathrm{t}=1, \ldots \mathrm{T}$ is the time period; $\mathrm{X}_{\mathrm{it}}$ is the symbol for the combination of all the exogenous variables in the model (fixed effects or time trend also included); $\rho_{\mathrm{i}}$ represents the autoregressive coefficients and finally $\varepsilon_{i t}$ is the error term. As explained in detail in Apergis and Payne (2010), Im et al. (2003) allows for different orders of serial correlation and follows the typical augmented Dickey Fuller (ADF) in average:

$$
\varepsilon_{i t}=\sum_{j=1}^{p=1} \varphi_{i j} \varepsilon_{i t-j}+u_{i t}
$$

If equation (4) is substituted into (3):

$$
y_{i t}=p_{i} y_{i t-1}+\sum_{j=1}^{p=1} \varphi_{i j} \varepsilon_{i t-j}+\delta_{i} X_{i t}+u_{i t}
$$

Where $\rho$ i shows the number of lags in the ADF regression. 
The test's null hypothesis is that each series in the panel dataset contains a unit root while alternatively, at least one of the individual series in the panel is stationary (no unit root). For robustness purposes, a battery of other unit root tests are also conducted to confirm the stationarity properties of our series. These tests include the Levin, Lin \&Chu $t$ statistic, the Breitung t-stat, the Im, Pesaran and Shin W-stat, the ADF Fisher Chi-square, and the PP Fisher Chi-square.

If the results of the test show that the series are stationary, then the analysis will proceed with the estimation of pooled effects model. Otherwise, Pedroni's (1999, 2004) panel cointegration test will be followed. This test allows for interdependence between cross sections, performed as in Apergis and Payne (2010):

$$
\begin{aligned}
& g d p_{\mathrm{it}}\left(\text { or gdppc } c_{\mathrm{it}}\right) \\
& =a_{i}+\delta_{i} t+\gamma_{1 i} \operatorname{tr} c_{i t}\left(\text { or } s r c_{i t}\right) \\
& +\gamma_{21} \operatorname{cop}_{i t}+\gamma_{3 i} e_{m p l} l_{i t}+\gamma_{4 i} r \& d_{i t}+\varepsilon_{i t}
\end{aligned}
$$

where $i=1, \ldots \mathrm{N}$ for each country; $\mathrm{t}=1, \ldots \mathrm{T}$ is the time period. The coefficients $\alpha_{i}$ and $\delta_{i}$ allow for country-specific fixed effects and deterministic trends, respectively while $\varepsilon_{\text {it }}$ denotes the estimated residuals representing deviations from the long-run. The null hypothesis is that there is no cointegration (in other words, the residuals are non-stationary). A unit root test is conducted as follows:

$$
\varepsilon_{i t}=\rho_{i} \varepsilon_{i t-1}+w_{i t}
$$

The panel tests proposed by Pedroni $(1999,2004)$ use the following four statistics: panel $v$, panel $\rho$, panel PP and panel ADF-statistic. "These statistics pool the autoregressive coefficients across different countries for the unit root tests on the estimated residuals. These statistics take into account common time factors and heterogeneity across countries. The group tests are based on the between dimension approach which includes three statistics: group r, group PP, and group ADF-statistics. These statistics are based on averages of the individual autoregressive coefficients associated with the unit root tests of the residuals for each country in the panel [10]". 
As Perman and Stern (2003) stress, the panel statistics are based on the work done on unit roots by Levin and Lin (1993) while the group statistics are following the ideas of Im et al. (1997).

If the results of the Pedroni test indicate that there is indeed cointegration among the variables in question then the exercise will proceed with the pooled and fixed effects estimation.

\subsection{Data}

The thirty four countries-members of OECD are chosen for the exercise for the following reasons. Firstly, among the OECD countries, there are both developed and developing countries, although the developing ones are admittedly a minority (2011). Second, their statistics are collected under this umbrella organization so there are no discrepancies in the definition of the variables and the units of measurement. Finally, all the OECD countries' policies have a certain level of homogeneity and commonalities.

Annual data from 1990 until 2010 were derived from the International Energy Agency, the World Development Indicators of the World Bank and the OECD Statistics for the thirty four OECD members. Real GDP and GDP per capita (constant prices 2005) is measured in US\$ converted with Purchase Power Parities (PPP); employment is measured in number of people employed in the country; capital is represented by the gross fixed capital formation in US \$ millions; the total renewable energy variable in kilotonne of oil equivalent and the share as a percentage ratio; finally, the R\&D expenditure in millions of US\$ in constant 2005 prices and PPPs. Due to missing data, especially for the R\&D expenditure series the following four countries were excluded from the analysis (Luxembourg, Chile, Turkey and Chile), leaving the panel with only 30 countries. 


\section{EMPIRICAL RESULTS}

As discussed in the methodology section the univariate characteristics of all the variables are tested with the unit root test proposed by Im et al. (2003). The null hypothesis of the test is that each series in the panel dataset contains a unit root while alternatively, at least one of the individual series in the panel is stationary (no unit root).

As shown in the Table A1, all the series are non-stationary. Hence, given the unit root results, the exercise proceeds by testing for the existence of cointegration.

Four different models are estimated to ensure the robustness of the results:

- Dependent variable: gdp

- Explanatory variables: cap, empl, r_d, trc

\section{Model 2}

- Dependent variable: gdp

- Explanatory variables: cap, empl, r_d, src

\section{$\underline{\text { Model } 3}$}

- Dependent variable: gdppc

- Explanatory variables: cap, empl, r_d, trc

\section{$\underline{\text { Model } 4}$}

- Dependent variable: gdppc

- Explanatory variables: cap, empl, r_d, src 
Where trc is the total renewable energy consumption; src is the share of renewable to total energy consumption; gdp is the gross domestic product; gdppc is the gross domestic product per capita; cap is the capital stock; empl is the employment level; $r$ d is the R\&D expenditure. The variables are in small letters to denote they are in their natural logarithmic form.

The preferred model here is the one that includes individual intercepts and trends, following Apergis and Payne (2010) estimation. As in Perman and Stern (2003), "Regressions without time dummies were not investigated as that case is of little practical importance given the consensus that time dummies are necessary to validate the conventional estimation assumption of crosssection independence.

Table 1 Panel cointegration test statistics

\begin{tabular}{|c|c|c|c|c|}
\hline & \multicolumn{2}{|c|}{ Model 1} & \multicolumn{2}{|c|}{ Model 2} \\
\hline & Panel & Group & Panel & Group \\
\hline$V$-stat & -1.368 & & 0.789 & \\
\hline$\rho$-stat & 3.924 & 5.968 & 4.825 & 6.376 \\
\hline$P P$-stat & -0.995 & $-4.616^{\mathrm{a}}$ & $-2.416^{\mathrm{a}}$ & $-6.398^{\mathrm{a}}$ \\
\hline \multirow[t]{3}{*}{$A D F$ stat } & $-1.492^{b}$ & $-3.175^{\mathrm{a}}$ & $-1.822^{b}$ & $-4.637^{\mathrm{a}}$ \\
\hline & \multicolumn{2}{|c|}{ Model 3} & \multicolumn{2}{|c|}{ Model 4} \\
\hline & Panel & Group & Panel & Group \\
\hline$V$-stat & $2.584^{\mathrm{a}}$ & & $1.475^{\mathrm{b}}$ & \\
\hline$\rho$-stat & 4.594 & 6.873 & 4.312 & 6.581 \\
\hline$P P$-stat & $-1.404^{\mathrm{b}}$ & $-4.401^{\mathrm{a}}$ & $-2.750^{\mathrm{a}}$ & $-5.468^{\mathrm{a}}$ \\
\hline$A D F$ stat & $-1.290^{\mathrm{c}}$ & $-2.321^{b}$ & $-1.500^{\mathrm{c}}$ & $-2.901^{\mathrm{a}}$ \\
\hline
\end{tabular}

Note: ${ }^{\text {a b }}{ }^{\mathrm{c}}$ denote $1 \%, 5 \%$ and $10 \%$ level of significance respectively; V, non-parametric variance ratio statistic; $\rho$, non-parametric test statistic analogous to the Phillips and Perron (PP) rho statistic; PP, non-parametric statistic analogous to the PP t statistic; ADF, parametric statistic analogous to the augmented Dickey-Fuller statistic. All statistics distributed as standard normal as $\mathrm{T}$ and $\mathrm{N}$ grow large. Null hypothesis: No cointegration. 
Table 1 presents the four different models and their Pedroni cointegration statistics. ${ }^{1}$ These statistics as Apergis and Payne (2010) explain, are based on the average values of the individual autoregressive coefficients linked with the unit root tests for each country in the panel. All the statistics are distributed asymptotically as normal standard. With the exception of the v-statistics and $\rho$-statistics, according to both panel and group PP and ADF statistics, the null hypothesis of no cointegration is rejected at the $1 \%$ level of significance.

The indication that cointegration exists in the four different models responds to two things. Firstly, the results are robust since change of the proxy for the economic conditions (gdp or gdppc) or the proxy for the renewable energy consumption (trc or src) does little to alter the conclusion of the tests. In addition, even though different specifications were included, the results confirm Apergis and Payne (2010) that there is indeed a long-run relationship between the economic conditions of a country and the renewable energy consumption, including the factors of production.

Next, after having established cointegration, the pooled regression is estimated and the results are presented in Table A2. The limitation of the pooled estimation is that it does not take into account heterogeneity among the cross-sections and hence, we continue with firstly a Hausman test to identify if either random or fixed effects are preferred for the specific estimation (the results are presented at Table A3). The Hausman test concludes that in all four models, the fixed effects estimation is preferred. Table 2 presents the results.

For the other factors of production (control variables), it can be noted that all the coefficients are positive and statistically significant and as expected the R\&D expenditures influence the GDP or GDP per capita less than capital and labour. The only exception is experienced with employment in models 3 and 4 whose coefficients appear to be negative and statistically insignificant; for this reason, in Table 2, models $3 \mathrm{a}$ and $4 \mathrm{a}$ are reported, In these two models, the employment variable is excluded; the coefficients for trc and src are very similar. Looking though at the overall fit of the estimations models $3 \mathrm{a}$ and $4 \mathrm{a}$ are better fits to the model.

\footnotetext{
${ }^{1}$ The author has also conducted a Granger causality analysis for the four models confirming that tre and src Granger cause gdp and gdppc for the models as mentioned above. The results of the short-run analysis are not reported here as they are not part of the scope of the paper but can be provided upon request.
} 
Table 2 Fixed effects estimation

\begin{tabular}{|l|c|c|c|c|c|c|}
\hline Models & $\mathbf{1}$ & $\mathbf{2}$ & $\mathbf{3}$ & $\mathbf{3 a}$ & $\mathbf{4}$ & $\mathbf{4 a}$ \\
\hline Dependent & $g d p$ & $g d p$ & $g d p p c$ & $g d p c c$ & $g d p p c$ & $g d p p c$ \\
\hline & & & & & & \\
\hline Trc & 0.105 & - & 0.103 & 0.100 & - & - \\
& $(13.024)^{\mathrm{a}}$ & & $(12.102)^{\mathrm{a}}$ & $(12.831)^{\mathrm{a}}$ & & \\
\hline Src & - & 0.089 & - & - & 0.088 & 0.090 \\
& & $(-7.180)^{\mathrm{a}}$ & & & $(10.432)^{\mathrm{a}}$ & $(11.846)^{\mathrm{a}}$ \\
\hline Cap & 0.298 & 0.302 & 0.340 & 0.367 & 0.343 & 0.378 \\
& $(19.389)^{\mathrm{a}}$ & $(18.906)^{\mathrm{a}}$ & $(20.875)^{\mathrm{a}}$ & $(29.565)^{\mathrm{a}}$ & $(20.437)^{\mathrm{a}}$ & $(30.363)^{\mathrm{a}}$ \\
\hline Empl & 0.433 & 0.486 & -0.055 & - & -0.003 & - \\
& $(8.976)^{\mathrm{a}}$ & $(9.796)^{\mathrm{a}}$ & $(-1.088)$ & & $(-0.054)$ & \\
\hline r_d & 0.186 & 0.202 & 0.148 & 0.122 & 0.164 & 0.142 \\
& $(15.466)^{\mathrm{a}}$ & $(16.356)^{\mathrm{a}}$ & $(11.635)^{\mathrm{a}}$ & $(12.244)^{\mathrm{a}}$ & $(12.599)^{\mathrm{a}}$ & $(14.180)^{\mathrm{a}}$ \\
\hline c & -3.882 & -4.288 & 0.396 & -0.884 & -0.002 & -0.728 \\
& $(-6.715)^{\mathrm{a}}$ & $(-7.180)^{\mathrm{a}}$ & $(0.648)$ & $(-3.578)^{\mathrm{a}}$ & $(-0.003)$ & $(-2.872)^{\mathrm{a}}$ \\
\hline & & & & & & \\
\hline Adj-R-sq & 0.999 & 0.999 & 0.981 & 0.980 & 0.979 & 0.980 \\
\hline F-statistic & 17448.26 & 16220.49 & 765.04 & 931.733 & 718.242 & 900.926 \\
\hline Akaike info & -3.230 & -3.157 & -3.117 & -3.074 & -3.055 & -3.041 \\
\hline Schwarz & -2.941 & -2.868 & -2.828 & -2.831 & -2.766 & -2.798 \\
\hline Hannan-Quinn & -3.116 & -3.044 & -3.004 & -2.980 & -2.942 & -2.947 \\
\hline
\end{tabular}

Notes: ${ }^{\mathrm{a}},{ }^{\mathrm{b}},{ }^{\mathrm{c}}$ denote $1 \%, 5 \%$ and $10 \%$ level of significance respectively; the figures in brackets denote the $\mathrm{t}$ statistics of the coefficients.

In all four models, both the coefficients for the total renewable energy consumption and the share of renewable energy consumption are positive and statistically significant at $1 \%$ level of significance. The coefficients of trc vary little from 0.105 (model 1) to 0.100 (model 3a). Expressing the variables in their natural logarithms, the coefficients can be explained as elasticity estimates. That means that for $1 \%$ increase of TRC, the GDP will rise by $0.105 \%$ while GDPPC will increase by $0.100 \%$. The influence of SRC to GDP and GPPC is slightly lower. If SRC increases by $1 \%$, then the GDP and GDPPC will increase by $0.089 \%$ and $0.090 \%$ respectively. These coefficients are marginally higher than 0.76 that was reported by Apergis and Payne (2010). The main reason for this difference is the inclusion of more countries in this exercise and most importantly the inclusion of the R\&D expenses as an additional factor of production. The findings are lower to the ones reported by Fang (2011) for the case of China. He finds that the 
coefficient for trc is 0.12 and 0.162 for gdp and gdppc; while for src it is 0.031 and 0.009 for gdp and gdppc respectively.

\section{DISCUSSION AND CONCLUSION}

The purpose of this paper is to determine quantitatively the impact of renewable energy consumption to the economic conditions in a panel data framework including all the OECD countries for the period from 1990 to 2010. The results of this analysis have important implications for the implementation of future policies on promoting renewable energies in combination with macroeconomic policies. The exercise employed annual data for the OECD countries from 1990 to 2010 within a multivariate framework based on the Cobb-Douglas production function.

The results of the Pedroni cointegration test reveal that there is a long-run equilibrium relationship between real GDP or real GDP per capita, total renewable energy consumption or share of total renewable energy consumption, real gross fixed capital formation, employment and the R\&D expenditures of the countries. The estimations indicate that a $1 \%$ increase of renewable energy consumption will increase GDP by $0.105 \%$ and GDP per capita by $0.100 \%$ while a $1 \%$ increase of the share of renewable energy to the energy mix of the countries will increase GDP by $0.089 \%$ and GDP per capita by $0.090 \%$.

These findings support the advantages of government policies promoting the use of renewable energy by establishing renewable energy markets, renewable energy portfolio standards not only to improve the environmental conditions but also from a macroeconomic point of view. By no means, this study proposes another macroeconomic policy; it only promotes the notion that policies in favor of renewable energies will at least not harm the economic welfare of the countries.

It should be noted here that we do appreciate the fact that higher economic growth might also be a factor to the level of renewable energy supply and consumption. However, this paper aimed at determining the impact of renewable energies to the economic growth of the OECD economies 
in an effort to assist policy makers before implementing new policies. The results also suggest that policy makers should not only focus on the rise of renewable energy consumption but also on its position and contribution to the overall energy mix.

\section{REFERENCES}

Apergis, N. and Payne, J.E. 2010. Renewable energy consumption and economic growth: evidence from a panel of OECD countries. Energy Policy. 38, 656-660.

Bugaje, I.M. 2006. Renewable energy for sustainable development in Africa: a review. Renewable and Sustainable Energy Reviews. 10, 603-612.

Cobb CW, Douglas PH. 1928. A theory of production'. American Economic Review. 18(Supplement), 139-165.

EC. Directive 2009/28//EC of the European Parliament and of the council of 23 April 2009 on the promotion of the use of energy from renewable sources and amending the subsequently repealing Directives 2001/77/EC and 2003/30/EC; 2009. Brussels, Belgium.

EIA. 2009. World Energy Demand and Economic Outlook of the 2009 International Energy Outlook; www.eia.doe.gov/oiaf/ieo/world.html.

Fang, Y. 2011. Economic welfare impacts from renewable energy consumption: the China experience. Renewable and Sustainable Energy Reviews. 15, 5120-5128.

Frondel, M., Ritter, N., Schimdt, C.M., and Vance, C. 2010. Economic impacts from the promotion of renewable energy technologies: The German experience. Energy Policy. 38, 4048-4056. 
Im, K., Pesaran, H. and Shin, Y. 1997. Testing for Unit Roots in Heterogeneous Panels, Discussion paper, revised version, June, University of Cambridge, Cambridge, UK.

Im, K.S., Pesaran, M.H., Shin, Y. 2003. Testing for unit roots in heterogeneous panels. Journal of Econometrics. 115, 53-74.

Inglesi-Lotz, R. and Blignaut, J.N. 2011. Electricity intensities of the OECD and South Africa: A comparison. Renewable and Sustainable Energy reviews. 16, 4491-4499.

IPCC. 2007. Fourth Assessment Report of the Intergovernmental Panel on Climate Change, Geneva, Switzerland.

Kaygusuz, K. 2007. Energy for sustainable development: key issues and challenges. Energy Sources, Part B: Economics, Planning, and Policy. 2, 73-83.

Kaygusuz, K., Yuksek, O., Sari, A. 2007. Renewable energy sources in the European union: markets and capacity. Energy Sources, Part B: Economics, Planning, and Policy. 2,1929.

Levin, A. and Lin, C. 1993. Unit Root Tests in Panel Data: Asymptotic and Finite-Sample Properties, Discussion paper, December, University of California, San Diego, US.

Menegaki, A.N. 2011. Growth and renewable energy in Europe: A random effect model with evidence for neutrality hypothesis. Energy Economics. 33:257-263.

Moselle, B. 2011. Why support renewables? EPRG spring research seminar. University of Cambridge. UK.

Munasinghe, M. 2010. Rural electrification in the Third World. Power Engineering journal 2010: 189-202.

Pedroni, P. 1999. Critical values for cointegration tests in heterogeneous panels with multiple regressors. Oxford Bulletin of Economics and Statistics. 61, 653-670. 
Pedroni, P. 2004. Panel cointegration: asymptotic and finite sample properties of pooled time series tests with an application to the PPP hypothesis: new results. Econometric Theory. $20,597-627$.

Pereira, M.G.,Freitas, M.A.V. and Silva, N.F. 2010. Rural electrification and energy poverty: empirical evidences from Brazil. Renewable and Sustainable Energy Reviews. 14,12291240.

Perman, R. and Stern, D.I. 2003. Evidence from panel unit root and cointegration tests that the Environmental Kuznets curve does exist. The Australian Journal of Agricultural and resource economics. 47, 325-347.

Sadorsky, P. 2009. Renewable energy consumption and income in emerging economies. Energy Policy. 37, 4021-4028.

Sari, R., Soytas, U. 2004. Disaggregate energy consumption, employment, and income in Turkey. Energy Economics. 26, 335-344.

Stigllitz, J. 2002. Globalization and its discontents. Penguin Books Ltd. London, UK.

Tugcu, C.T., Ozlturk, I, Aslain, A. 2012. Renewable and non-renewable energy consumption and eocnomic growth revisited: Evidence from G7 countries. Energy economics. 34, 19421950. 


\section{APPENDIX}

Table A1: Panel unit root test

\begin{tabular}{|c|c|c|c|c|c|c|c|c|c|c|c|}
\hline Variable & Form & Method & Statistic & P-value & Conclusion & Variable & Form & Method & Statistic & P-value & Conclusion \\
\hline \multirow[t]{12}{*}{ cap } & $\begin{array}{l}\text { Trend and } \\
\text { intercept }\end{array}$ & LLC & 2.083 & 0.981 & non-stationary & $\mathrm{src}$ & Trend and intercept & LLC & 3.014 & 0.999 & non-stationary \\
\hline & & Breit t & -0.889 & 0.187 & non-stationary & & & Breit t & 4.781 & 1.000 & non-stationary \\
\hline & & IPS & -3.359 & 0.000 & stationary & & & IPS & 4.334 & 1.000 & non-stationary \\
\hline & & ADF-Fisher & 120.834 & 0.000 & stationary & & & ADF-Fisher & 50.513 & 0.851 & non-stationary \\
\hline & & PP-Fisher & 84.560 & 0.030 & stationary & & & PP-Fisher & 42.172 & 0.975 & non-stationary \\
\hline & Intercept & LLC & -2.181 & 0.015 & stationary & & Intercept & LLC & 3.461 & 1.000 & non-stationary \\
\hline & & IPS & 1.878 & 0.970 & non-stationary & & & IPS & 3.006 & 0.999 & non-stationary \\
\hline & & ADF-Fisher & 37.578 & 0.994 & non-stationary & & & ADF-Fisher & 56.722 & 0.666 & non-stationary \\
\hline & & PP-Fisher & 31.523 & 1.000 & non-stationary & & & PP-Fisher & 52.678 & 0.795 & non-stationary \\
\hline & None & LLC & 5.811 & 1.000 & non-stationary & & None & LLC & 1.083 & 0.861 & non-stationary \\
\hline & & ADF-Fisher & 10.171 & 1.000 & non-stationary & & & ADF-Fisher & 49.956 & 0.864 & non-stationary \\
\hline & & PP-Fisher & 12.817 & 1.000 & non-stationary & & & PP-Fisher & 46.632 & 0.927 & non-stationary \\
\hline Variable & Form & Method & Statistic & P-value & Conclusion & Variable & Form & Method & Statistic & P-value & Conclusion \\
\hline \multirow[t]{12}{*}{ empl } & $\begin{array}{l}\text { Trend and } \\
\text { intercept }\end{array}$ & LLC & -1.059 & 0.145 & non-stationary & $\operatorname{trc}$ & Trend and intercept & LLC & -6.390 & 0.000 & stationary \\
\hline & & Breit t & 2.897 & 0.998 & non-stationary & & & Breit t & 0.816 & 0.793 & non-stationary \\
\hline & & IPS & -0.330 & 0.371 & non-stationary & & & IPS & -1.422 & 0.078 & non-stationary \\
\hline & & ADF-Fisher & 90.316 & 0.011 & stationary & & & ADF-Fisher & 92.619 & 0.007 & stationary \\
\hline & & PP-Fisher & 78.317 & 0.079 & non-stationary & & & PP-Fisher & 74.828 & 0.127 & non-stationary \\
\hline & Intercept & LLC & -0.883 & 0.189 & non-stationary & & Intercept & $\mathrm{LLC}$ & 2.728 & 0.997 & non-stationary \\
\hline & & IPS & 1.456 & 0.927 & non-stationary & & & IPS & 5.309 & 1.000 & non-stationary \\
\hline & & ADF-Fisher & 58.716 & 0.595 & non-stationary & & & ADF-Fisher & 92.699 & 0.007 & stationary \\
\hline & & PP-Fisher & 55.019 & 0.723 & non-stationary & & & PP-Fisher & 24.052 & 1.000 & non-stationary \\
\hline & None & $\mathrm{LLC}$ & 9.255 & 1.000 & non-stationary & & None & LLC & 3.714 & 1.000 & non-stationary \\
\hline & & ADF-Fisher & 10.165 & 1.000 & non-stationary & & & ADF-Fisher & 23.639 & 1.000 & non-stationary \\
\hline & & PP-Fisher & 9.489 & 1.000 & non-stationary & & & PP-Fisher & 18.869 & 1.000 & non-stationary \\
\hline
\end{tabular}




\begin{tabular}{|c|c|c|c|c|c|c|c|c|c|c|c|}
\hline Variable & Form & Method & Statistic & P-value & Conclusion & Variable & Form & Method & Statistic & P-value & Conclusion \\
\hline \multirow[t]{25}{*}{ r_d } & $\begin{array}{l}\text { Trend and } \\
\text { intercept }\end{array}$ & LLC & -0.952 & 0.171 & non-stationary & $\operatorname{gdp}$ & Trend and intercept & LLC & 6.524 & 1.000 & non-stationary \\
\hline & & Breit t & 2.920 & 0.998 & non-stationary & & & Breit t & 4.945 & 1.000 & non-stationary \\
\hline & & IPS & -0.998 & 0.159 & non-stationary & & & IPS & 2.956 & 0.998 & non-stationary \\
\hline & & ADF-Fisher & 93.981 & 0.005 & stationary & & & ADF-Fisher & 52.641 & 0.796 & non-stationary \\
\hline & & PP-Fisher & 42.418 & 0.973 & non-stationary & & & PP-Fisher & 50.765 & 0.845 & non-stationary \\
\hline & Intercept & LLC & -2.850 & 0.002 & stationary & & Intercept & LLC & -6.744 & 0.000 & stationary \\
\hline & & IPS & 3.872 & 1.000 & non-stationary & & & IPS & 0.345 & 0.635 & non-stationary \\
\hline & & ADF-Fisher & 37.210 & 0.995 & non-stationary & & & ADF-Fisher & 65.366 & 0.361 & non-stationary \\
\hline & & PP-Fisher & 64.636 & 0.385 & non-stationary & & & PP-Fisher & 51.783 & 0.819 & non-stationary \\
\hline & None & LLC & 12.139 & 1.000 & non-stationary & & None & LLC & 19.013 & 1.000 & non-stationary \\
\hline & & ADF-Fisher & 3.398 & 1.000 & non-stationary & & & ADF-Fisher & 2.098 & 1.000 & non-stationary \\
\hline & & PP-Fisher & 2.896 & 1.000 & non-stationary & & & PP-Fisher & 0.244 & 1.000 & non-stationary \\
\hline & & & & & & Variable & Form & Method & Statistic & P-value & Conclusion \\
\hline & & & & & & gdppc & Trend and intercept & LLC & -10.546 & 0.000 & stationary \\
\hline & & & & & & & & Breit t & 5.167 & 1.000 & non-stationary \\
\hline & & & & & & & & IPS & -14.669 & 0.000 & stationary \\
\hline & & & & & & & & ADF-Fisher & 287.680 & 0.000 & stationary \\
\hline & & & & & & & & PP-Fisher & 377.407 & 0.000 & stationary \\
\hline & & & & & & & Intercept & LLC & -13.457 & 0.000 & stationary \\
\hline & & & & & & & & IPS & -16.121 & 0.000 & stationary \\
\hline & & & & & & & & ADF-Fisher & 354.728 & 0.000 & stationary \\
\hline & & & & & & & & PP-Fisher & 978.683 & 0.000 & stationary \\
\hline & & & & & & & None & LLC & -23.392 & 0.000 & stationary \\
\hline & & & & & & & & ADF-Fisher & 548.352 & 0.000 & stationary \\
\hline & & & & & & & & PP-Fisher & 592.767 & 0.000 & stationary \\
\hline
\end{tabular}

Note: ${ }^{\text {a }},{ }^{\text {b }}{ }^{\mathrm{c}}$ denote $1 \%, 5 \%$ and $10 \%$ level of significance respectively; trc is the total renewable energy consumption; src is the share of renewable to total energy consumption; gdp is the gross domestic product; cap is the gross fixed capital formation; empl is the employment level; $\mathrm{r}_{-} \mathrm{d}$ is the R\&D expenditure; LLC is the Levin, Lin \&Chu $\mathrm{t}$ statistic; Breit $\mathrm{t}$ is the Breitung t-stat; IPS is the Im, Pesaran and Shin W-stat; ADF-Fisher is the ADF Fisher Chi-square; PP-Fisher is the PP Fisher Chi-square. The null hypothesis of the test is that at least one of the series contains a unit root. The variables are in small letters to denote they are in their natural logarithmic form. 
Table A2: Pooled estimation

\begin{tabular}{|l|c|c|c|c|}
\hline Models & $\mathbf{1}$ & $\mathbf{2}$ & $\mathbf{3}$ & $\mathbf{4}$ \\
\hline Dependent & $g d p$ & $g d p$ & gdppc & gdppc \\
\hline & & & & \\
\hline Trc & 0.027 & - & 0.040 & - \\
& $(4.030)^{\mathrm{a}}$ & & $(5.682)^{\mathrm{a}}$ & \\
\hline Src & - & 0.035 & - & 0.046 \\
& & $(4.863)^{\mathrm{a}}$ & & $(6.094)^{\mathrm{a}}$ \\
\hline Cap & 0.254 & 0.264 & 0.298 & 0.310 \\
& $(13.762)^{\mathrm{a}}$ & $(14.271)^{\mathrm{a}}$ & $(15.533)^{\mathrm{a}}$ & $(16.116)^{\mathrm{a}}$ \\
\hline empl & 0.587 & 0.603 & -0.521 & -0.498 \\
& $(44.230)^{\mathrm{a}}$ & $(46.990)^{\mathrm{a}}$ & $(-37.829)^{\mathrm{a}}$ & $(-37.303)^{\mathrm{a}}$ \\
\hline r_d & 0.166 & 0.169 & 0.211 & 0.216 \\
& $(13.966)^{\mathrm{a}}$ & $(14.403)^{\mathrm{a}}$ & $(17.064)^{\mathrm{a}}$ & $(17.642)^{\mathrm{a}}$ \\
\hline c & -4.446 & -4.818 & 8.675 & 8.191 \\
& $(-16.446)^{\mathrm{a}}$ & $(-17.226)$ & $(30.924)^{\mathrm{a}}$ & $(28.148)^{\mathrm{a}}$ \\
\hline & & & & \\
\hline Adj-R-sq & 0.991 & 0.991 & 0.808 & 0.811 \\
\hline F-statistic & 14365.01 & 14569.13 & 544.670 & 550716 \\
\hline Akaike info & -0.959 & -0.973 & -0.885 & -0.894 \\
\hline Schwarz & -0.918 & -0.932 & -0.844 & -0.853 \\
\hline Hannan- & -0.943 & -0.957 & -0.869 & -0.878 \\
Quinn & & & & \\
\hline
\end{tabular}

Notes: a , b c denote $1 \%, 5 \%$ and $10 \%$ level of significance respectively; the figures in brackets denote the t-statistics of the coefficients.

Table A3: Hausman test

\begin{tabular}{|l|c|c|c|c|}
\hline Models & $\mathbf{1 a}$ & $\mathbf{2 a}$ & $\mathbf{3 a}$ & $\mathbf{4 a}$ \\
\hline Chi-sq stat & 12.560 & 8.238 & 141.055 & 117.544 \\
\hline$D f$ & 4 & 4 & 4 & 4 \\
\hline$p$-value & 0.013 & 0.083 & 0.000 & 0.000 \\
\hline Conclusion & Fixed & Fixed & Fixed & Fixed \\
\hline
\end{tabular}

